\title{
Cyclic CPT Measurements of Disturbed Soil State
}

\author{
Aleksandra Katarzyna Koteras ${ }^{1}$, Tomas Sabaliauskas ${ }^{2}$, and Lars Bo Ibsen ${ }^{3}$ \\ ${ }^{1}$ Department of Civil Engineering, Aalborg University, Thomas Manns Vej 23 Aalborg, Denmark. \\ E-mail: ak1@civil.aau.dk \\ ${ }^{2}$ Department of Civil Engineering, Aalborg University, Thomas Manns Vej 23 Aalborg, Denmark. \\ E-mail: ts@civil.aau.dk \\ ${ }^{3}$ Department of Civil Engineering, Aalborg University, Thomas Manns Vej 23 Aalborg, Denmark. \\ E-mail: $\underline{\text { lbi@civil.aau.dk }}$
}

\begin{abstract}
Disturbed soil states in geotechnical problems occurs together with large uncertainties. During earthquake, disturbed sand can become either more or less resistant to liquefaction. Due to the cyclic loading, offshore wind turbine foundations can episodically loose or recover the stiffness. In both cases, the initial in-situ soil state is lost, as disturbed soil state evolves during cyclic loading. Thus, it is important to develop a testing procedure that combines observations of both the initial condition and the long-term disturbed soil state. This paper presents the results of cone penetration tests (CPT-s). A conventional use of CPT leads to undisturbed soil results. However, the paper describes a non-conventional use of this method, where CPT is performed multiple times in the same location. The first penetration measures the undisturbed sand strength and stiffness, whereas the second and later penetrations observe evolving disturbed state of sand. The 'cyclic CPT' curve of cone resistance $q_{c}$ converges while repeating the test, resulting in a final disturbed soil profile for initial sand state.
\end{abstract}

Keywords: Sand; disturbed soil; CPT; cyclic behavior.

\section{Introduction}

Cone penetration test (CPT) is a widespread-used method for testing soil parameters of undisturbed, in-situ soil, where cone resistance $q_{c}$ is measured as cone penetrates the soil (Robertson 1990; Lunne et al. 1997). However, for some geotechnical problems it is not enough to know the initial (undisturbed) soil state. Both, strength and stiffness of soil can change while it is being disturbed. Disturbed soil states can develop due to earthquakes or other sources of cyclic loads. For example, offshore wind turbine foundation stiffness is affected by disturbed soil states caused by wind, waves and moving components (Damgaard et al. 2013). Introduction of novel testing procedures is called for to address the geotechnical problems (National Research Council 2006), where one of those is a behavior of disturbed state of sand. There is a general lack of consensus regarding the effects of cyclic preloading of sand (di Prisco and Wood 2012). Therefore, methods for observation of cyclic disturbed sand need to be developed, and a standard CPT evolved into 'cyclic CPT' could potentially be used for the purpose.

Cone resistance measured during the test depends on the peak strength and the stiffness of the soil. Disturbed sand can both loose and recover stiffness and strength, but there is a lack of models or experimental observations combining the two effects into one continuous sequence. Unfortunately, it is not clear how much of the measured $q_{c}$ depends on changes in stiffness or on the strength (di Prisco and Wood 2012). The idea for executing cyclic CPT was in part inspired by recent advances in triaxial testing (Sabaliauskas and Ibsen 2017), (Sabaliauskas 2018). In a triaxial apparatus, a sand specimen was disturbed by pulling it back to initial length after testing peak strength. The disturbed sand stiffness hysteresis loops converged in direct proportion to applied deformation amplitude. Changes in disturbed sand stiffness were not sensitive to variation in density, as disturber sand stiffness hysteresis loops converged in proportion exclusively to applied deformation amplitude. Similarly, CPT generates deformation of constant amplitude, as the cone has a constant diameter. Thus, a significant part of disturbed $q_{c}$ adaptation could be caused by changes in disturbed sand stiffness rather than strength (or density).

There is a low confining pressure at shallow penetration depths that strongly affects the cone resistance, what should be considered while testing test in small-medium scale testing equipment. By collecting the data of CPT Puech and Foray (2002) observed two penetration phases, where the first can be described by a parabolic increase in $q_{c}$ with a depth and the second is based on a quasi-stationary value of $q_{c}$ that become constant with a depth. The transition depth between those phases is defined by critical depth $D_{c}$, fig. 1.In the first phase the upward movement of sand creates a heave on the soil surface and in the second phase the failure is only limited to the close vicinity of the cone tip. In preparation for cyclic CPT, it was expected that two phases are possible to detect for loose to medium dense sand. However, the second quasi-stationary phase could not be detected in dense and very dense sand. Moreover, disturbed sand cone resistance $\left(q_{c}\right)$ in dense sand is expected to be lost due to dilation, while loose sand should rather increase in $q_{c}$ due to compaction.

\author{
Proceedings of the 7th International Symposium on Geotechnical Safety and Risk (ISGSR) \\ Editors: Jianye Ching, Dian-Qing Li and Jie Zhang \\ Copyright (c) ISGSR 2019 Editors. All rights reserved. \\ Published by Research Publishing, Singapore. \\ ISBN: 978-981-11-2725-0; doi:10.3850/978-981-11-2725-0_IS12-14-cd
}




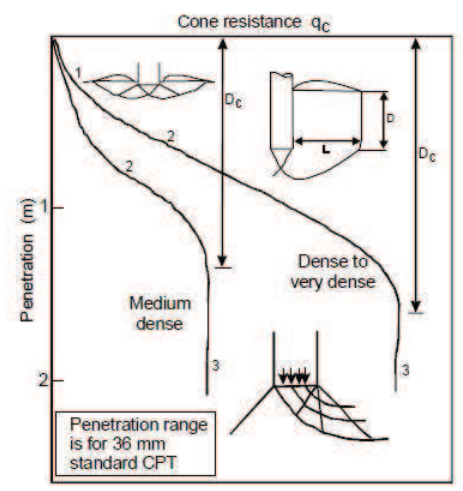

Figure 1. Failure mechanisms for different phases of cone penetration (Puech and Foray 2002).

The cyclic CPT is a novel procedure, but yet does not require new equipment. It can be implemented in industry and research applications without additional expenses. The cyclic CPT is based on repeating the test in the same location more than once. First penetration measures the equivalent of initial (in-situ, undisturbed) soil state whereas following penetrations measure $q_{c}$ in disturbed soil state left after previous test. This allows measuring how fast the soil profile converges when it is disturbed repeatedly. The novel procedure has the potential to approximate how much strength and stiffness in-situ soil can lose and gain while it is being disturbed. This could improve reliability of cyclic loaded structure design as well as provide new data sets for more fundamental research of disturbed soil properties.

\section{Methods}

A CPT device of laboratory size was used for the soil investigation. The cone has a diameter of $15 \mathrm{~mm}$ with $30^{\circ}$ inclination and the length allow for a penetration of $1100 \mathrm{~mm}$. Cone resistance $q_{c}$ is measured by a load cell made of 4 strain gauges coupled in a full-bridge connection, placed just below the cone. The penetration rate was set to $5 \mathrm{~mm} / \mathrm{s}$. The CPT device is shown in Fig. 2.

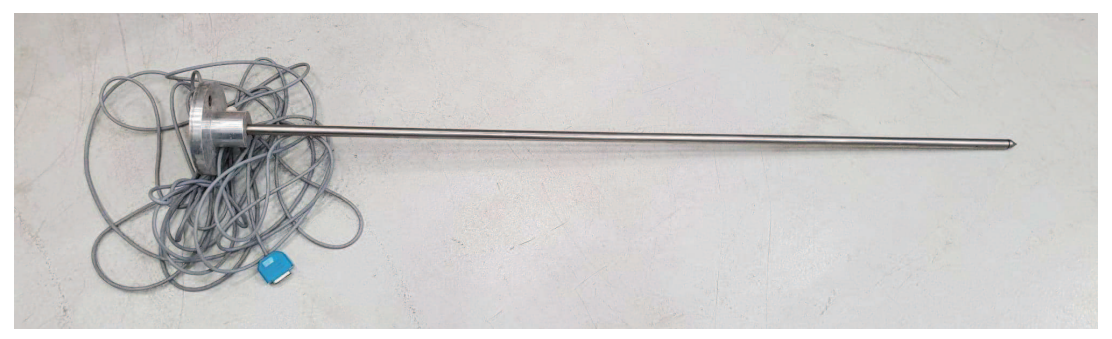

Figure 2. Laboratory CPT device.

Baskarp Sand No. 15 was used for testing, Tab.1. The sand is deposited in a large cylindrical box; $2.5 \mathrm{~m}$ of diameter and $3.5 \mathrm{~m}$ of height. The box is filled with $0.3 \mathrm{~m}$ of gravel and $2.2 \mathrm{~m}$ of sand. The sand box is an extended version of a 'yellow box' used primarily for testing the medium scale monopoles and bucket foundations in Aalborg University laboratory (Thomassen et al. 2017; Vaitkunaite et al. 2017; Koteras and Ibsen 2019). Sand is saturated with a drainage system containing perforated pipes equally placed within the layer of gravel. A felt cloth is placed at the top of gravel layer to avoid small sand particles from entering the drainage pipes. The water level was situated above soil surface when testing. 
Table 1. Parameters for Baskarp Sand (Nielsen and Nielsen 2018).

\begin{tabular}{ccccc}
\hline $\begin{array}{c}\text { Specific grain } \\
\text { density, } \mathrm{d}_{\mathrm{s}}\left[\mathrm{g} / \mathrm{cm}^{3}\right]\end{array}$ & $\begin{array}{c}\text { Maximum void } \\
\text { ratio, } \mathrm{e}_{\max }[-]\end{array}$ & $\begin{array}{c}\text { Minimum void } \\
\text { ratio, } \mathrm{e}_{\min }[-]\end{array}$ & $\begin{array}{c}50 \% \text { - quantile, } \\
\mathrm{d}_{50}[\mathrm{~mm}]\end{array}$ & $\begin{array}{c}\text { Uniformity coefficient, } \\
\mathrm{U}=\mathrm{d}_{50} / \mathrm{d}_{10}[-]\end{array}$ \\
\hline 2.64 & 0.858 & 0.549 & 0.14 & 1.78 \\
\hline
\end{tabular}

Tests were executed at different sand densities between loose to very dense sand. Freshly deposited sand has low density, however, already indicating a density at the border between medium dense and loose sand. To increase the density, sand is vibrated using an industrial vibrator (Koteras 2017). However, the vibrator extend is approximately $1 \mathrm{~m}$ of depth. The vibration must be repated many times before obtaining a very dense sand of relative density $D_{R}$ around $80-90 \%$. Between vibrations a CPT and a foundation testing can be executed for different sand densities. After high density is reached, it can be reduced back to initial loose condition by applying a vertical gradient big enough to liquefy the entire soil volume (quick sand condition). Alternatively, a thin pipe can be used to inject high-pressure water in multiple locations across the deposited sand making localized, liquefied piping channels. If multiple piping channels are generated close to each other - a uniform, low density sand condition can be achieved. The loosest state obtained was for $D_{R}=37 \%$.

The interpretation of CPT results is based on previously published triaxial test results on Baskarp Sand with different void ratios and confining pressures (Ibsen and Brødker 1994; Ibsen et al. 1995; Borup and Hedegaard 1995). Relative density is based on $q_{c}$ and stress level. A formulation was found from direct measurements of relative density previously tested by CPT, Eq.(1). The formulation for the friction angle $\varphi_{\text {tr }}$ and $50 \%$ strength secant modulus $E_{50}$ were calibrated based on triaxial tests, Eqs.(2-3). Reference stress level $\sigma_{r e f}^{\prime}$ for interpretation of friction angle is $5 \mathrm{kPa}$. However, for stiffness calculation the only available reference stress value is $100 \mathrm{kPa}$, therefore, the accuracy is effected (Ibsen et al. 2009). Both friction angle and stiffness depends on $D_{R}$ and stress level. The cohesion of sand is denoted as $c$ and is also calibrated from triaxial tests. However, the stiffness possibly also depends on the history of deformation when analyzing the disturbed sand state (Sabaliauskas and Ibsen 2017). This is not included in the calibration of formula.

$$
\begin{aligned}
& D_{R}=5.14\left(\frac{\sigma^{\prime}{ }_{v 0}}{q_{c}^{0.75}}\right)^{-0.42} \\
& \varphi_{t r}=0.152 \cdot D_{R}+27.4 \cdot\left(\frac{\sigma_{v 0}^{\prime}}{\sigma_{r e f}^{\prime}}\right)^{-0.28}+23.2 \\
& E_{50}=E_{50}^{r e f}\left(\frac{c \cos (\varphi)+\sigma_{3}^{\prime} \sin (\varphi)}{c \cos (\varphi)+\sigma_{3}^{\prime r e f} \sin (\varphi)}\right)^{m} \\
& E_{50}^{r e f}=0.6322 D_{R}^{2.507}+10920
\end{aligned}
$$

As the soil relative density is calculated based on the vertical effective stress $\sigma^{\prime}{ }_{v 0}$, calculation method requires estimation of soil unit weight $\gamma$. The unit weight of sand is obtained from the optimization of in-situ void ratio $e_{i n-s i t u}$ between a minimum and a maximum value of $e$ from Tab.1 by using Eqs. (5-6) (Carter and Bentley 2016). $S$ is the degree of saturation.

$$
\begin{aligned}
& \gamma=\frac{d_{S}+e \cdot S}{1+e} \gamma_{w} \\
& D_{R}=\frac{e_{\max }-e_{\text {in }- \text { situ }}}{e_{\max }-e_{\min }}
\end{aligned}
$$

For the disturbed state of sand (cyclic CPT from second cycle), the stress level is kept the same. The unit weight of soil is calculated only for $1^{\text {st }}$ cycle in each set of cyclic CPT data, and used for the remaining cycles.

\section{Results}

Tests analyzed for this paper were performed in sand of different initial state between loose to very dense sand. The relative density of its initial state, Eq.(1), calculated based on the first CPT, describes a set of cyclic CPT tests for each initial state. The compaction level indicates loose sand $\left(0.2-0.4 D_{R}\right)$, medium dense (04-0.6 $\left.D_{R}\right)$, dense (0.6-0.8 $\left.D_{R}\right)$ and very dense $\left(>0.8 D_{R}\right)$ sand condition. The changes in cone resistance $q_{c}$ are analyzed. Fig. 3 presents $q_{c}$ for all CPT cycles for initial sand of $D_{R}=37 \%$ (loose sand) and $D_{R}=83 \%$ (very dense sand). 


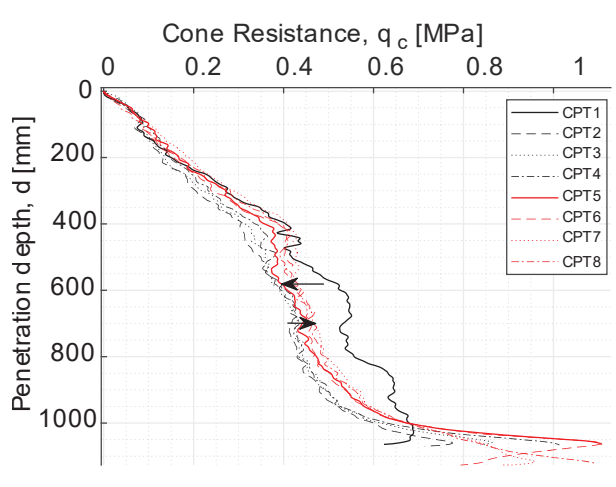

a.

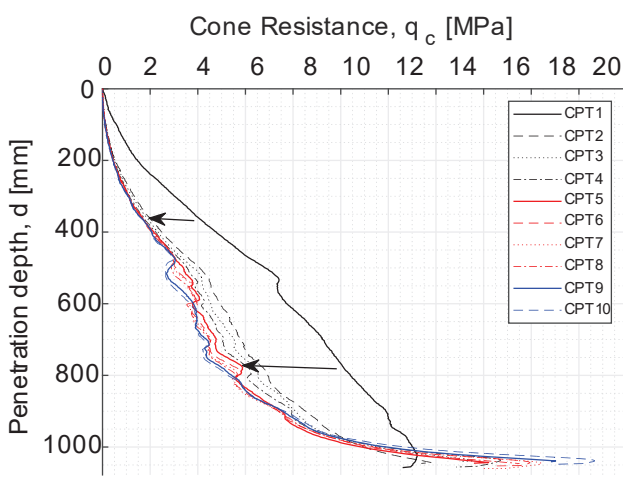

b.

Figure 3. Results of cone resistance for cyclic CPT: (a.) $D_{R}=37 \%$ and (b.) $D_{R}=83 \%$.

By analyzing only $1^{\text {st }}$ cycle for each of initial state only one phase of CPT behavior described by Puech and Foray (2002) can be distinguish - a parabolic increase in cone resistance. The increase after $600 \mathrm{~mm}$ is, however, a bit less significant for loose sand but to assume that the transition depth is in so shallow depth, more tests are required. In most of these tests, a drop of $q_{\mathrm{c}}$ in initial CPT is observed at the depth of approximately $1000 \mathrm{~mm}$. This drop is due to the vibration depth extend, as the vibrator can reach approximately around $1000 \mathrm{~m}$, meaning that sand below is not compacted during this procedure. Finally, cone penetration resistance increase more than 10 times when comparing test in loose and very dense sand.

The cyclic CPT results show that the resistance of soil is decreasing with cycles, but with more stabilization trend from around $8^{\text {th }}-10^{\text {th }}$ cycle. This is valid for all tests in medium dense to very dense sand. For loose sand the resistance is also reduced by $2^{\text {nd }}$ cycle, but after that it starting to increase again, however within the limit of $1^{\text {st }}$ and $2^{\text {nd }}$ cycle. Moreover, the most of change in all of initial sand states is observed between $1^{\text {st }}$ and $2^{\text {nd }}$ cycle. Also for all of tests, a substantial increase in resistance is seen where the penetration stops. Location at which the cone merely touches the sand and then penetrates it again with a following cycle gains a lot of resistance. However, this strong layer is only a localized phenomenon, as the resistance is dropped again if further penetrating. This increase is advancing with each cycle, reaching even up to $100 \%$ of $q_{c}$ for loose sand and almost $50 \%$ of $q_{c}$ in very dense sand, after $8^{\text {th }}$ and $10^{\text {th }}$ cycle respectively.

Results of soil parameters are derived from equations presented in section 2, based on the measured cone resistance. They are calculated for depth of $100 \mathrm{~mm}-800 \mathrm{~mm}$, as the first $100 \mathrm{~mm}$ is not reliable due to the close distance to the surface and the last $200 \mathrm{~mm}$ is excluded so the layers that may not be vibrated or may be merely vibrated will not be included. The most interesting here is the change in those parameters due to CPT cycles. The results of the change between the $1^{\text {st }}$ and the $9^{\text {th }} / 10^{\text {th }}$ cycle are presented in Table 2. For loose sand, test no.2, the maximum change happened after $2^{\text {nd }}$ cycle, and therefore this change is presented in the table.

Table 2. Results of 'cyclic CPT'.

\begin{tabular}{cccccc}
\hline Test no. & $\begin{array}{c}\text { Initial } D_{R} \\
{[\%]}\end{array}$ & $\begin{array}{c}\text { Average decrease in } \\
q_{c}[\%]\end{array}$ & $\begin{array}{c}\text { Average } \\
\text { decrease in } D_{R} \\
{[\%]}\end{array}$ & $\begin{array}{c}\text { Average } \\
\text { decrease in } \varphi_{t r} \\
{[\%]}\end{array}$ & $\begin{array}{c}\text { Average } \\
\text { decrease in } \\
E_{50}[\%]\end{array}$ \\
\hline 02 & 37 & $19.7\left({\left.\text { after } 2^{\text {nd }} \text { cycle }\right)}\right.$ & 7.2 & 0.9 & 6.1 \\
\hline 03 & 58 & 35.4 & 12.5 & 2.2 & 18.4 \\
\hline 04 & 67 & 52.1 & 19.2 & 3.9 & 32.7 \\
\hline 05 & 78 & 46.6 & 17.1 & 3.9 & 31.8 \\
\hline 06 & 83 & 53.5 & 22.2 & 5.3 & 41.8 \\
\hline
\end{tabular}

Finally, it is interesting to observe how the void ratio is changing due to the cycles. As the void ratio depends also on the stress level it is presented for different level of vertical stress by extracting value on given depth between 100 to $800 \mathrm{~mm}$. The horizontal stress level is not presented, as the assumption on lateral earth pressure coefficient $K_{0}$ could be far from reality as there are boundary conditions included and the sand was vibrated before testing. Both could influence the $K_{0}$ significantly. Fig. 4 compares the changes in void ratio for tests $02-05$ and 06 as a representation of loose, medium dense, dense and very dense sand condition. 


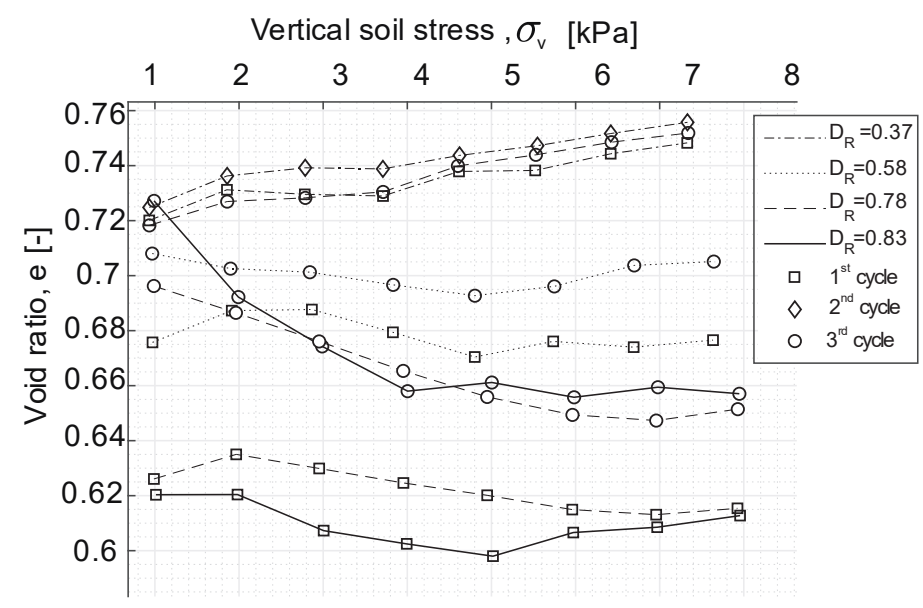

Figure 4. Comparison of void ratio change due to cycles for different initial sand state.

Interestingly, the void ratio for Baskarp Sand at failure based on triaxial tests results (Ibsen and Brødker 1994 ) is equal $0.88,0.75$ and 0.68 for reference stress level $\sigma_{3}$ 'of 5 for sample with $D_{R}$ equal to $0.01,0.51$ and 0.8 respectively. Disregarding results for $1-2 \mathrm{kPa}$ stress level, which have a small accuracy due to extremely small stress level, the void ratio is rather far from those void ratio at failure.

\section{Discussion}

The cyclic CPT could be used to estimate the loss of strength and stiffness of long-term behavior of in-situ sand. It can also reveal how many cycles it takes for the disturbed soil layers to stabilize. It remains true that density and $q_{c}$ are proportional - larger density produces significantly larger $q_{c}$ during the first loading cycle. Knowing this, it was expected that disturbed sand would correlate with density: dense sand was expected to lose $q_{c}$ faster due to dilation, while loose sand was expected to generate increasing $q_{c}$ due to compaction. However, the loss of $q_{c}$ is present in both dense and loose sand, but the compaction and decreasing void ratio is observed with more cycle in loose state. The compaction due to failure could possibly be even more visible when analyzing more loose sand. This trend for loose sand requires more tests for validation; however, such a loose sand is difficult to obtain in the sand container used for this research and it is less interesting for the design, as such a loose sand is not observed in real life. Nevertheless, it can be concluded that the range of changes in resistance depends on the density of initial state of sand. The more sand is compacted, the more of resistance due to cyclic CPT is lost. Finally, the increasing in resistance observed at the final depth of each cycle could be contributed to the increase in both strength and stiffness; however, it is only a localized phenomenon.

The most important finding from this research is how the soil strength and stiffness parameters change due to the cyclic behavior of sand. First, the changes are correlated with the density of sand. The more compacted the sand is, the more significant are changes. More important is the fact, that the change in friction angle is between $5-1 \%$ of change from its initial value for very dense to loose sand respectively. The change in stiffness on the example of $E_{50}$ is between $42-6 \%$ of change, again for very dense to loose sand respectively. For the cyclic design the stiffness parameter plays a very important role, therefore, the cyclic CPT could potentially allow for the fast approximation of this change.

Lastly, the changes in void ratio presented in Fig.4 allows following the changes in density between the $1^{\text {st }}$ and the last presented cycle (also $2^{\text {nd }}$ cycle included for loose sand) according to the level of vertical stress. The localized failure around the cone during the penetration do not cause the entire soil failure, as the values are far from the void ratio at failure. The changes in void ratio are more significant for more compacted sand. However, for such a shallow depth and small stress level, it is hard to distinguish that the void ratio is also changed with the stress level. This should be clearer while analyzing a full scale CPT.

\section{Conclusion}

The conventional well-known CPT procedure has been used to test disturbed soil state due to the cyclic loading. The cycles where limited to maximum 10 cycles, to show that the cone resistance recorded during the CPT is reduced during the cycles for medium dense sand to very dense sand and the value of cone resistance is approximately converged to a stable value after 10 cycles. The resistance of loose sand is reduced for the $2^{\text {nd }}$ 
cycle, but then it starts to increase again with the following cycles. These trends can be correlated to the wellknown behavior of sand, where the dense sand experiences dilation and the loose sand is subjected to compaction.

The strength and stiffness parameters were calculated based on results of cone resistance and triaxial tests. Even though the precision of results is not high due to the low stress level, the base conclusion on the results can be made. The change in soil strength and stiffness due to the cyclic CPT depend on the initial state of sand; changes are more significant for more compacted sand used for testing. What is more, the changes in stiffness are always much more significant from the changes in friction angle. The stiffness drops by $42 \%$ to $6 \%$ for very dense to loose dense respectively. The change in friction angle is only by maximum $5 \%$ ( $1 \%$ for loose sand).

The topic of disturbed sand brings forth a lot of fundamental questions, which could be answered by observing how disturbed soil states evolve and what they converge to - in unconventional 'cyclic CPT', using standard equipment. The topic deserves a further research extended for the normal scale CPT.

\section{References}

Borup, M. and Hedegaard, J. (1995). Baskarp Sand No. 15: Data Report 9403. Geotechnical Engineering Group, Aalborg University.

Carter, M. and Bentley, S. (2016). Soil Properties and Their Correlations. 1 red, West Sussex, UK: John Wiley \& Sons.

Damgaard, M., Ibsen, L., and Andersen, L. (2013). Cross-wind modal properties of offshore wind turbines identified by full scale testing. Journal of Wind Engineering and Industrial Aerodynamics, Årgang 116, 94-108.

di Prisco, C. and Wood, D. (2012). Mechanical Behaviour of Soils Under Environmentally-Induced Cyclic Loads, Vienna: Springer.

Dobry, R. and Abdoun, T. (2015). Cyclic shear strain needed for liqueafaction triggering and assessment of overburden pressure factor K_sigma. Journal of Geotechnical and Geoenvironmental Enginerring, 141(11).

Ibsen, L., Borup, M., and Hedegaard, J. (1995). Data Report 9501, Triaxial Tests on Baskarp Sand No. 15, Geotechnical Engineering Group, Aalborg University.

Ibsen, L. and Brødker, L. (1994). Data Report 9301, Baskarp Sand No.15, Geotechnical Engineering Group, Aalborg University.

Ibsen, L., Hanson, M., and Thaarup, M. (2009). MC-Parameter Calibration of Baskarp Sand No. 15, Department of Civil Engineering, Aalborg University.

Koteras, A. (2017). Set-up and Test Procedure for Suction Installation and Uninstallation of Bucket Foundation, Department of Civil Engineering, Aalborg University.

Koteras, A. and Ibsen, L. (2019). Medium-scale laboratory model of mono-bucket foundation for installation tests in sand. Canadian Geotechnical Journal, 56(8), 1142-1153.

Lunne, T., Robertson, P., and Powell, J. (1997). Cone Penetration Testing in Geotechnical Practice, New York: Blackie Academic, EF Spon/Routledge Publishing.

National Research Council (2006). Geological and Geotechnical Engineering in the New Millenium: Opportunities for Research and Technological Innovation, Washington, DC: National Academies Press.

Nielsen, S. and Nielsen, B. (2018). Data report on Baskarp Sand No. 15, Aalborg Universitet, Institut for Byggeri og Anlæg.

Puech, A. and Foray, P. (2002). Refined Model for Interoreting Shallow Penetration CPTs in Sands, Houston, Texas, Proc., Offshore Technology.

Robertson, P. (1990). Soil classification using the cone penetration test. Canadian Geotechnical Journal, 27(1), 151-158.

S.D.Nielsen, L.B. (2015). Dynamic behavior of mono bucket foundations subjected to combined transient loading. The $3 \mathrm{rd}$ Internationl symposium on Frontiers in offshore Geotechnics, 1, 313-318.

Sabaliauskas, T. (2018). Deformation Dependent States in Cyclic Disturbed Sand, Aalborg University.

Sabaliauskas, T. and Ibsen, L. (2017). Triaxial Testing Beyond Yielding, San Francisco, California, International Society of Offshore \& Polar Engineers.

Thomassen, K., Ibsen, L., and Andersen, L. (2017). Laboratory test setup for cyclic axially loaded piles in sand. Journal of Geotechnical Engineering, 22(3), 1089-1106.

Vaitkunaite, E., Ibsen, L., and Nielsen, B. (2017). Bucket foundation model testing under tensile axial loading. Canadian Geotechnical Journal, 54(5), 720-728. 